Aletria, Belo Horizonte, v. 29, n. 1, p. 91-109, 2019

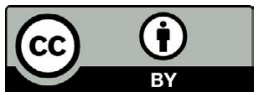

\title{
Desire, desire, desire: uma paródia de Christopher Durang ao teatro estadunidense
}

\section{Desire, Desire, Desire: Christopher Durang's \\ Parody of The North-American Theater}

\section{Fulvio Torres Flores}

Universidade Federal do Vale do São Francisco, Juazeiro, Bahia / Brasil

fulviotf@uol.com.br

Fabiano Tadeu Grazioli

Universidade Regional Integrada do Alto Uruguai e das Missões, Erechim, Rio Grande do Sul / Brasil

Faculdade Anglicana de Erechim, Erechim, Rio Grande do Sul / Brasil tadeugraz@yahoo.com.br

Resumo: A peça em um ato Desire, desire, desire (1995), de Christopher Durang, parodia uma série de peças do teatro estadunidense, algumas já consideradas clássicas como Um bonde chamado desejo e Gata em telhado de zinco quente, de Tennessee Williams, e outras bastante conhecidas, como O homem de gelo, de Eugene O'Neill, Boa noite, mãe, de Marsha Norman, O sucesso a qualquer preço, de David Mamet, e Meu amigo Harvey, de Mary Chase. Todas essas peças foram adaptadas para o cinema e fazem parte, em menor ou maior medida, do repertório cultural da população. Com base em textos que tratam de intertextualidade e paródia, procuramos demonstrar como Durang cria a sua paródia e como sua peça responde a discussões pertinentes no final do século XX, que não estavam postas ou eram apenas incipientes nas décadas em que tais textos foram criados.

Palavras-chave: teatro estadunidense; intertextualidade; paródia; Um bonde chamado desejo; Gata em telhado de zinco quente. 
Abstract: The one-act play Desire, desire, desire (1995), by Christopher Durang, parodies a number of North-American plays, some of them considered classics such as A streetcar named desire and Cat on a hot tin roof, by Tennessee Williams, and other well-known, such as The iceman cometh, by Eugene O'Neill, Night, mother, by Marsha Norman, Glengarry Glen Ross, by David Mamet, and Harvey, by Mary Chase. All of these plays have been adapted to the big screen and are part, to a lesser or greater extent, of people's cultural repertoire. Based on bibliography that deals with intertextuality and parody, we sought to show how Durang develops his parody and how his play responds to relevant discussions of the end of 20th century, not brought into light still incipient in the previous decades in which the plays and films were created.

Keywords: North-American theater; one-act play; intertextuality; parody; A Streetcar named desire; Cat on a hot tin roof.

\section{Introdução}

Christopher Durang, estadunidense nascido em 1949, é um autor ativo na cena teatral de seu país. Sua carreira teve início nos anos 1970, quando começou a escrever peças apresentando discussões relacionadas à homossexualidade, ao abuso infantil, aos dogmas religiosos e à vida cultural da "América". Em 2013, foi agraciado com o mais importante prêmio de teatro nos Estados Unidos, o Tony de melhor peça por Vanya and Sonia and Masha and Spike (Vanya e Sonia e Masha e Spike). ${ }^{1}$ Essa peça, uma comédia que evoca nomes de personagens, situações e espaços de algumas obras dramatúrgicas do russo Anton Tchékhov - entre elas $A s$ três irmãs, Tio Vânia e O jardim das cerejeiras - foi sucesso não apenas na Broadway, mas também encenada em São Paulo, em 2015, com direção de Jorge Takla. Assim como Vanya and Sonia and Masha and Spike, outra peça longa que se destaca na carreira de Durang é Sister Mary Ignatius explains it all for you (Irmã Maria Inácio explica tudo para você), de 1979.

Além de peças longas, o autor escreveu uma série de peças curtas em um ato, o que tem permitido a diretores(as) montar programas específicos com algumas delas, de acordo com seus interesses. Publicado em 1998 pela Dramatists Play Service, conceituada editora especializada

\footnotetext{
${ }^{1}$ Os títulos das obras de Christopher Durang e das obras por ele parodiadas serão apresentados primeiro em inglês e, em seguida, em tradução para o português. Ao longo do texto, serão mantidos os títulos na língua inglesa. Outras obras citadas serão referidas diretamente em português.
} 
em textos dramatúrgicos estadunidenses e também em clássicos estrangeiros traduzidos para o inglês, o volume Naomi in the living room and other plays: a collection of one-acts by Christopher Durang (Naomi na sala de estar e outras peças: uma coletânea de peças em um ato escritas por Christopher Durang) apresenta três seções: "Character comedies and sketches" (Comédias de personagem e cenas), com 13 peças; "Parodies" (Paródias), com quatro peças; e "Political" (Políticas), com seis peças.

Das quatro peças paródicas do volume Naomi in the living room and other plays, apenas uma não parodia o teatro. Trata-se de The Hardy Boys and the mystery of where babies come from (Os Garotos Valentes e o mistério de onde vêm os bebês), que apresenta Frank e Joe Hardy, ${ }^{2}$ personagens que se envolvem em mistérios numa série televisiva transmitida de 1977 a 1979 pela ABC nos Estados Unidos, com Parker Stevenson (Joe) e Shaun Cassidy (Frank) nos papéis principais. As outras três têm como base textos dramatúrgicos de diferentes autores e lugares.

Medea (Medeia), escrita em parceria com sua conterrânea Wendy Wasserstein, é uma brevíssima paródia da Medeia clássica de Eurípedes, incluindo um hilário início no qual a atriz que interpreta a personagem principal se dirige ao público e discursa sobre a escassez de bons papéis femininos nas artes, citando como exceção o filme Thelma e Louise, de 1991, dirigido por Ridley Scott, e a peça As troianas (também de Eurípedes). Mesmo se tratando de uma peça curta, Durang não deixou de incluir o coro (elemento essencial na tragédia grega), agora recriado com função cômica.

Aunt Dan meets the Madwoman of Chaillot (Tia Dan encontra a Louca de Chaillot) põe em confronto paródico duas personagens, a Tia, a partir da peça Aunt Dan and lemmon (Tia Dan e limão), do estadunidense Wallace Shawn, escrita em 1985, e a Louca, de La Folle de Chaillot (A Louca de Chaillot), do francês Jean Giraudoux, que estreou em 1945. O encontro entre Tia Dan, uma mulher verborrágica e de opiniões fascistas, criada por Shawn, agora conversa com a Louca de Chaillot de Giradoux, em geral entendida como personagem que livra o mundo do mal (ela manda executar os empresários que estão destruindo Paris), mas que na versão de Durang ganha contornos parecidos com o de Tia Dan.

Desire, desire, desire (Desejo, desejo, desejo), peça de que trata este artigo, é a mais "americana" das paródias no volume, uma vez que

\footnotetext{
${ }^{2}$ O título da série tem duplo sentido: "Hardy", além do sobrenome dos garotos, também significa "valente, corajoso".
} 
faz referência a peças diversas de autores daquele país: A streetcar named desire (Um bonde chamado desejo - 1947) e Cat on a hot tin roof (Gata em telhado de zinco quente - 1955), ambas de Tennessee Williams; The iceman cometh (O homem de gelo - 1946), de Eugene O'Neill, 'Night, mother (Boa noite, mãe - 1982), de Marsha Norman; Glengarry Glen Ross (O sucesso a qualquer preço - 1983), de David Mamet; Harvey (Meu amigo Harvey - 1944), de Mary Chase. Nesta peça em um ato, encontramos Blanche e Stanley morando juntos após Stella, seis anos antes, ter saído para comprar uma Coca-Cola para a irmã e não ter retornado. A ação se passa em tempo contínuo em um apartamento velho em Nova Orleans, onde Blanche e Stanley recebem visitas inesperadas.

\section{A paródia como elemento intertextual}

Se tomarmos as acepções mais comuns da palavra "intertextualidade", conforme Houaiss, encontraremos alguns elementos coincidentes, nos quais um texto estabelece relações com outro texto do mesmo autor ou de autor diferente, sejam essas relações baseadas na influência direta de um texto modelo ou de vários textos que permitem a elaboração de um novo. ${ }^{3}$ E se por texto entendermos toda produção verbal, não verbal, audiovisual, etc., que apresenta para um determinado grupo social um sentido específico, aí podemos nos dar conta da imensidão de intertextos nos quais sempre estivemos mergulhados.

A tragédia grega já fazia uso desse recurso, uma vez que seus textos escritos tinham como fonte os mitos da tradição oral. No século XX e neste início do XXI, vemos as séries de televisão e os filmes dialogarem com a literatura de forma cada vez mais ampla e irrestrita, assim como as artes visuais e performáticas o fazem entre si e com outros textos, provando que a relação intertextual não precisa obedecer qualquer limite, estando à disposição da criatividade de autores e do efeito que pretendem criar. A mais recente "invenção" intertextual são, possivelmente, os memes e os gifs, que misturam imagem estática ou em movimento com texto, e requerem do espectador o conhecimento de fatos históricos, arte, literatura, política, entre outros. Essa incessante capacidade de desenvolvimento da intertextualidade talvez nos permita

${ }^{3} \mathrm{Cf}$. INTERTEXTUALIDADE. 
concordar, sem remorsos, com a afirmação de Voltaire de que "Tudo é imitação [...] Os espíritos mais originais pisoteiam uns nos outros". ${ }_{4}$

Embora tenha sido desde sempre muito usada por literatos, a intertextualidade só passou a ser estudada mais consistentemente como um recurso de caráter próprio e digno de análise no século XX. É a autora búlgaro-francesa Julia Kristeva quem cunha o termo "intertextualidade", segundo Alfaro, em

"A palavra, o diálogo e o romance" (1966) e depois em "O texto fechado" (1966-67), ensaios que ela escreveu pouco após sua chegada a Paris, vindo de sua terra natal, a Bulgária. O conceito de intertextualidade que ela iniciou propõe o texto como um terreno dinâmico no qual processos e práticas relacionais são o foco da análise no lugar de estruturas e produtos estáticos. ${ }^{5}$

Ainda segundo Alfaro, ${ }^{6}$ Kristeva desenvolveu o conceito bakhtiniano de espacialização da linguagem literária. Para Kristeva, a palavra literária é "[...] mais uma intersecção de superfícies textuais do que um ponto (um significado fixo), como um diálogo entre vários escritos". 7 Esse texto de Alfaro oferece breves, porém consistentes, reflexões sobre uma gama de teóricos que se debruçaram sobre as questões da intertextualidade, sejam os da Antiguidade, como Platão, Aristóteles e Horácio, sejam os do século XX, como Roland Barthes, Tzvetan Teodorov, Michel Foucault e Linda Hutcheon.

É a partir dos escritos de Hutcheon em Uma teoria da paródia: ensinamentos das formas de arte do século XX (1985) que embasaremos nossas considerações. A autora canadense também escreveu, entre outros,

${ }^{4}$ VOLTAIRE apud TELES. A retórica do silêncio: teoria e prática do texto literário, p. 33. 5 “'Word, Dialogue and Novel' (1966) and then in 'The Bounded Text' (1966-67), essays she wrote shortly after arriving in Paris from her native Bulgaria. The concept of intertextuality that she initiated proposes the text as a dynamic site in which relational processes and practices are the focus of analysis instead of static structures and products." (ALFARO. Intertextuality: origins and development of the concept, p. 268, tradução nossa).

${ }^{6}$ ALFARO. Intertextuality: origins and development of the concept, p. 268.

7 " [...] an intersection of textual surfaces rather than a point (a fixed meaning), as a dialogue among several writings." (KRISTEVA. Word, dialogue, and novel apud ALFARO. Intertextuality: origins and development of the concept, p. 268, tradução nossa). 
Uma teoria da adaptação (2006). Os títulos deixam claro, pelo uso do artigo indefinido no início de cada um, que Hutcheon propõe ao leitor uma interpretação sobre os fenômenos que analisa, sem com isso fechar a possibilidade de outras interpretações.

Antes de entrar propriamente nas considerações de Hutcheon, vale a pena ainda dizer que a intertextualidade pode se apresentar de diferentes maneiras. Os tipos mais comuns são paródia, paráfrase, epígrafe, citação, alusão e tradução. Já fixando-nos na paródia, que é o tipo intertextual mais produtivo para análise do texto Desire, desire, desire, de Christopher Durang, é importante esclarecer que a palavra paródia tem origem no grego antigo - para (paralelo, contra) e ode (canto) -, e significa "canto paralelo" ou "contracanto" (a depender da tradução). Essa palavra aparece na Poética de Aristóteles quando o autor fala sobre as espécies de poesia imitativa, classificando Homero como um imitador de homens superiores e "Hegemontes de Tasos - que foi o primeiro autor de paródias - e Nicochares, autor da Deilíada, representaram pessoas de caráter inferior." Como informado pelo tradutor da Poética na mesma página na nota 22, há quem acredite que a Deilíada pode ser sido uma paródia da Ilíada, obra atribuída a Homero. Em grego deilia significa covardia, exatamente o contrário dos grandes feitos heroicos presentes na Ilíada. Percebe-se, assim, que a paródia desde os tempos antigos já era associada, por sua natureza, à comédia, visto que esse gênero se diferenciava da tragédia justamente pelo tipo de personagem que privilegiava expor ao espectador. Assim, a paródia visa criticar com ironia e humor a sua fonte textual.

Hutcheon, porém, não se restringe a este entendimento de paródia e propõe outro, no qual é preciso recuperar uma acepção da palavra grega para, menos conhecida, que significa "ao longo de". Se "canto paralelo" e "contracanto" apresentam a ideia de textos que em alguma medida contrastam e se opõem, o sentido recuperado por Hutcheon abre uma possibilidade mais concreta de interpretação:

A paródia é, pois, na sua irônica 'transcontextualização' e inversão, repetição com diferença. Está implícita uma distanciação crítica entre o texto em fundo a ser parodiado e a nova obra que incorpora, distância geralmente assinalada pela ironia. ${ }^{9}$

\footnotetext{
${ }^{8}$ ARISTÓTELES. Poética, p. 42.

${ }^{9}$ HUTCHEON. Uma teoria da paródia, p. 48.
} 
Além desta ampliação conceitual, Hutcheon defende a paródia das constantes acusações de ser inimiga da criação "original" (como se isso fosse realmente possível, afinal cria-se a partir de algum conhecimento prévio, vivência, conjunto de leituras, etc.), afirmando que esses ataques provêm de uma herança da estética romântica apreciadora da originalidade e da individualidade. ${ }^{10}$ Além disso, seu aspecto ligado ao humor e ao cômico muitas vezes pode dar a entender, para os leitores menos preparados, que se trata de uma mera ridicularização do textofonte. $\mathrm{O}$ ato de parodiar pode ser crítico e marcar a diferença entre os textos através da ênfase nas suas diferenças. Para Hutcheon, "[u]ma nova forma desenvolve-se a partir da antiga, sem na realidade a destruir; apenas a função é alterada. [...] A paródia torna-se, pois, um princípio construtivo na história literária." 11

\section{Desire, desire, desire: a paródia em um ato de Durang}

Em seu livro Teoria do drama moderno, Peter Szondi vai direto ao ponto ao afirmar que a peça em um ato é uma forma distinta do drama convencional burguês (estruturado em geral em três ou mais atos), "[...] não apenas quantitativa, mas também qualitativamente: na natureza da ação que decorre e - intimamente vinculado com ela - na natureza do momento de tensão." ${ }^{12} \mathrm{Na}$ peça em um ato, o(a) autor(a) opta por relativizar a intersubjetividade sem permitir que ela domine a ação, ou, ainda, provoca o seu total esfacelamento, no qual o diálogo já não pode ser mais entendido como uma construção lógica em torno de algo a que se quer chegar. Por essa razão, Szondi vai afirmar que a peça em um ato tem como firme elemento de constituição a situação dramática, mas não a ação, pois a ação no drama convencional pode ser modificada continuamente pelos personagens até o desenlace, já a peça em um ato "já não extrai mais a tensão do fato intersubjetivo, esta deve já estar ancorada na situação."13

Desire, desire, desire tem como fontes peças deste drama construído ainda com forte base na intersubjetividade (embora seja imprescindível notar que $A$ streetcar named desire tem uma série de

\footnotetext{
${ }^{10}$ HUTCHEON. Uma teoria da paródia, p. 14.

${ }^{11}$ HUTCHEON. Uma teoria da paródia, p. 52.

${ }^{12}$ SZONDI. Teoria do drama moderno, p. 110.

${ }^{13}$ SZONDI. Teoria do drama moderno, p. 110.
} 
elementos épicos que certamente a constituem como uma peça legítima do drama moderno, não mais burguês). e vai, como constata Szondi, abrir mão da construção intersubjetiva lógica a fim de permitir aquilo que é o interesse de Durang através de sua criação em um ato: a paródia. Para tanto, Durang recorre à forma do teatro do absurdo.

Hend Khalil, ${ }^{14}$ reunindo diversas fontes, apresenta em seu artigo sobre as peças de Durang For whom the Southern belle tolls (de 1993) e Desire, desire, desire, a importância do teatro do absurdo na análise de ambas. Não cabe aqui repetir cada um dos argumentos da autora, cuja leitura do artigo recomendamos, mas é interessante apresentar os principais pontos reunidos, em que os autores do absurdo propõem: a) um estilhaçamento da forma teatral convencional, isto é, a ordenação lógica de acontecimentos com começo, meio e fim, e a distribuição das ações a partir da relação intersubjetiva; b) uma prevalência da falta de sentido em detrimento da pretensa construção de um sentido; c) uma linguagem próxima ao cotidiano, mas repleta de incoerências, fissões, repetições e espaços não preenchidos; d) essa mesma linguagem como algo passível de reestrutura e recriação. Khalil conclui que "[i]nfluenciado pela tríade confirmação-aceitação-realização sugerida por [Albert] Camus para encontrar um modo de encarar a vida absurda e fútil, Durang parodiou as inconsistências na condição humana." 15

Se o uso da forma da peça em um ato cria espaço para que o foco narrativo incida sobre a situação, o teatro do absurdo é a forma que estrutura a narrativa, e a paródia estabelecerá a relação intertextual com as peças do teatro estadunidense. Apresentaremos a seguir os nomes dos personagens e de quais personagens das peças-fonte eles derivam. Por fim, seguirá a análise da paródia entremeada pelo resumo específico do contexto de cada uma das peças parodiadas.

Os personagens principais são Blanche e Stanley, baseados em Blanche Dubois e Stanley Kowalski, de A streetcar named desire. Dessa

\footnotetext{
${ }^{14}$ KHALIL. Revisiting the Theatre of the Absurd in Christopher Durang's For whom the Southern belle tolls (1993) and Desire, desire, desire (1995).

15 “'Influenced by Camus' suggested acknowledgement-acceptance-accomplishment triad to find a way to face the absurd futile life, Durang has parodied the inconsistencies in the human condition." (KHALIL. Revisiting the Theatre of the Absurd in Christopher Durang's For whom the Southern belle tolls (1993) and Desire, desire, desire (1995), p. 151, tradução nossa).
} 
mesma peça há ainda os personagens Stella (Stella Kowalski) e Jovem (Young Man). Paizão (Big Daddy) e Maggie (Maggie, a Gata) provêm de Cat on a hot tin roof, e Maggie 2 é uma espécie de duplo de Maggie, aparecendo apenas na paródia. Cora é de The iceman cometh. As outras peças citadas como referência são parodiadas através da fala de alguns desses personagens citados. O próprio Durang ${ }^{16}$ inclui um brevíssimo posfácio à peça a fim de esclarecer as fontes e sanar possíveis dúvidas do público leitor.

Faz-se notar a importância que a construção da imagem tem na peça. Em $A$ streetcar named desire, Stanley é um homem simples e que beira a grosseria em algumas de suas ações e falas, aspecto apresentado logo de início na peça de Durang, de forma hiperbólica. Essa imagem se constrói em vários aspectos: o primeiro é que ele está sem camiseta, o que remete a uma das cenas mais lembradas na peça, desde a atuação de Marlon Brando no final dos anos 1940 na Broadway, e depois eternizada no cinema na primeira adaptação realizada por Elia Kazan (com Vivien Leigh como Blanche). Em seguida, ele quebra a garrafa de cerveja em sua própria cabeça e joga o que restou do casco no chão. Abrindo outra garrafa, bebe metade do conteúdo e joga o restante em cima de sua camiseta. Blanche, tentando parecer elegante, vestida com uma roupa com babados, toma um coquetel e estremece levemente diante das ações dele. Essa cena acontece sem troca de palavras, que seriam desnecessárias, pois o autor parece saber muito bem o que está no imaginário de seu público, por isso o reconhecimento dos personagens é feito de imediato.

A entrada de Maggie em cena também remete a um elemento visual bastante conhecido em Cat on a hot tin roof: a combinação (ou camisola - no original, slip) sexy usada em cenas que envolvem sedução, roupa bastante conhecida pelo público e que ficou eternizada no corpo de Elizabeth Taylor, intérprete da Gata no cinema. Da mesma peça, Paizão, conforme descrito na rubrica por Durang, deve usar preenchimento de barriga, tornando-o ainda mais gordo do que a personagem criada pelo ator Burl Ives e registrado na clássica versão fílmica de 1958 (este é o mesmo filme em que Elizabeth Taylor atua), dirigida por Richard Brooks. Por fim, quando o homem aparece ao final com traje de coelho, temos outra cena alusiva tanto à peça Harvey, de Mary Chase, quanto ao filme homônimo de Henry Koster, de 1950, no qual Elwood (interpretado por

${ }^{16}$ DURANG. Naomi in the living room and other plays, p. 205. 
James Stewart) é um homem que apresenta o coelho Harvey, um amigo imaginário, a seus amigos e sua família.

Como se pode perceber, a presença das imagens criadas pela cinematografia estadunidense tem papel relevante para a compreensão das imagens paródicas da peça curta, uma vez que a sétima arte - e sua propagação via televisão e, mais recentemente, plataformas de exibição e sites de vídeos - tem grande penetração no imaginário do público.

Khali $^{17}$ faz observações acertadas a respeito de dois elementos que são importantes e bem detalhados em $A$ streetcar named desire, não enfatizados por Durang: a descrição do espaço e a música. O autor da paródia se limita apenas a dizer que a ação se passa num apartamento velho de Nova Orleans e a única inserção de música se dá no final da peça, com um saxofone triste acompanhando a última fala de Stanley e o gesto desolado de Blanche. O uso da música na peça de Williams, seja o blue piano ou a polka varsoviana, se faz notar porque ele está associado a reminiscências da personagem principal e à menção de desastre ou morte.

É nas palavras que a força paródica de Desire, desire, desire reside. A começar pelo título, que faz referência ao nome do bonde (chamado desejo) da peça mais parodiada e a uma das mais importantes características de sua personagem principal, Blanche Dubois, cuja "queda trágica" se inicia por ceder a seus desejos mais instintivos. As três palavras em sequência serão repetidas diversas vezes durante a peça.

A representação de Stanley como um ser rude e de pouca inteligência é um aspecto constantemente reforçado, pois ele demonstra não saber o que são coisas simples, como um sedativo e uma urna grega. Além disso, Blanche afirma que ele é bastante desleixado, não lava o cabelo e sequer usa desodorante. Isso está em contraste à peça original, porque embora Stanley não tenha tido o mesmo nível de acesso à educação formal que foram dados a Blanche e Stella, não se pode considerá-lo um ignorante. Entre outras coisas, ele demonstra conhecer, por exemplo, o código napoleônico, que lhe dá direito sobre os bens da esposa (e vice-versa), logo, se ela foi enganada por Blanche (de quem ele suspeita), ele foi enganado em igual medida. O Stanley original é, de fato, um homem com inteligência prática para os fatos da vida e sua

${ }^{17}$ KHALIL. Revisiting the Theatre of the Absurd in Christopher Durang's For whom the Southern belle tolls (1993) and Desire, desire, desire (1995), p. 146-147. 
rudeza em alguns momentos pode ser vista como uma defesa às investidas de Blanche contra ele.

Durang também ironiza a cultura de sua Blanche. A Blanche de $A$ streetcar named desire é segura de sua educação formal e insere em suas falas menções à cultura erudita e à arte, por exemplo, quando afirma a Stella que "Talvez nós ainda estejamos muito longe de ser feitos à imagem de Deus, mas, Stella - minha irmã - houve algum progresso desde então! Coisas como a arte - e a poesia e a música - uma nova espécie de luz veio ao mundo desde então." ${ }^{18}$ Quando a Blanche de Desire, desire, desire faz o mesmo, o resultado é cômico: ao afirmar para o Jovem que Stanley não aprecia poesia e "recusa as concepções elevadas de Wordsworth, Sheets and Kelly", ${ }^{19}$ ela faz uma verdadeira bagunça com os nomes dos poetas que afirma admirar. E a correção aos nomes não vem facilmente: "Kates e Shelley. Keets e Shelley. E Gerald Manley Hophead. Hopscotch. Ah, estou muito confusa". ${ }^{20}$ Os nomes de William Wordsworth (o único que ela acerta de primeira), John Keats e Percy B. Shelley, poetas românticos ingleses, vêm seguidos do último nome, com o qual ela comete dois erros: o primeiro nome é Gerard e o último é Hopkins. São todos poetas românticos ingleses que não são mencionados em $A$ streetcar named desire por Blanche; porém são citados os escritores Nathaniel Hawthorne, Walt Whitman e Edgard Allan Poe, românticos estadunidenses. A Blanche de Durang quer atravessar as águas do Atlântico para citar seus românticos, mas naufraga na tentativa.

Sobre Gerard Manley Hopkins é importante acrescentar que se trata de um padre jesuíta e poeta da era vitoriana cuja obra só foi reconhecida no século XX e que, apesar de controvérsias críticas, apresenta forte caráter homoerótico. O homoerotismo é um elemento que paira em ambas as peças de Williams e que Durang não vai deixar de parodiar.

O Jovem, que em $A$ streetcar named desire aparece brevemente e troca poucas palavras com Blanche, tem permanência mais ampla na peça em um ato. Nessa última, ele é um agente censitário que chega para fazer

\footnotetext{
${ }^{18}$ WILLIAMS. Um bonde chamado desejo, p. 125.

19 "rejects the elevated visions of Wordsworth, Sheets and Kelly." (DURANG. Naomi in the living room and other plays, p. 195, tradução nossa).

20 "Kates and Shelley. Keets and Shelley. And Gerald Manley Hophead. Hopscotch. Oh, I'm all confused." (DURANG. Naomi in the living room and other plays, p. 195, tradução nossa).
} 
perguntas típicas dessa profissão. Após algumas investidas de Blanche para que ele vá com ela para o quarto enquanto ele tenta fazer perguntas sérias sobre a vida social e política, fica sabendo que ela dorme com o leiteiro, o entregador de papel e o chef francês da confeitaria. Tudo isso é dito em frente a Stanley, cuja única reação é dizer que "[c]onfeitaria francesa é bichice." ${ }^{21} \mathrm{Na}$ peça-fonte, Blanche dorme com rapazes mais jovens e acaba se envolvendo com um aluno menor de idade, o que provoca sua expulsão da escola onde leciona inglês e literatura. $\mathrm{O}$ fato é mantido em segredo por Blanche, mas Stanley descobre e usa-o para atacar a cunhada. Na paródia, em que eles vivem juntos desde que Stella saiu para comprar a Coca-Cola e não retornou, não há nenhuma forma de repreensão dele ou tentativa dela para esconder os fatos.

A entrevista do Jovem é interrompida por uma sucessão de entradas e saídas de personagens. A primeira delas é de Maggie, que confunde Stanley com Brick (seu marido desinteressado em sexo em Cat on a hot tin roof) e diz-lhe que Paizão (pai dele) está morrendo de câncer e quer que o filho e ela gerem um herdeiro, terminando por perguntar-lhe se ele quer que o irmão, a cunhada e seus filhos fiquem com a fortuna da família. Toda a fala vem despejada de uma vez e resume o conflito da peça-fonte: Maggie, a Gata, quer engravidar e dar a Paizão um neto gerado por seu filho favorito. A Maggie da peça curta afirma ter dislexia e por isso se desculpa por entrar no apartamento errado, pois confunde os números na porta.

Cora, uma prostituta de The iceman cometh, entra para contar sua conversa com Hickey, um vendedor, e de como ele falou contra levar a vida com pipe dreams ("sonhos impossíveis" ou "castelos no ar"). Cora repete a expressão tantas vezes que irrita Blanche, e esta lhe sugere usar apenas illusion (ilusão). Cora ataca Blanche chamando-a de velha, feia e afirmando que ela terminará numa instituição, isto é, Cora descreve exatamente o final dela em $A$ streetcar named desire, pois Blanche se sente velha e feia, rejeitada por Mitch, um pretendente a casamento, e é levada a uma instituição de tratamento mental, após ter sido estuprada por Stanley e perder de vez a conexão com a realidade.

Blanche ameaça se matar após a atitude de Cora, o que parodia a fala da personagem Jessie de 'Night, mother, na qual ela faz uma lista

21 "French pastries are sissy." (DURANG. Naomi in the living room and other plays, p. 194, tradução nossa). 
- antes de se suicidar - indicando para a mãe onde encontrar coisas que ela vai precisar para manter a rotina diária. A lista de Blanche inclui itens que são importantes para ela, como lanternas de papel, que estarão com "sonhos destruídos e filtros extras para o aspirador de pó" 22 em um armário, e os utensílios com tema da Torre Eiffel, com o espremedor de suco de laranja, os guardanapos e "pedaços espalhados do meu coração". ${ }^{23 .}$ Há uma mistura entre o ordinário e o poético ao listá-los. Outros itens pessoais que remetem à narrativa de $A$ streetcar named desire são cartas de amor e toalhas, com as quais ela quer ser enterrada. $\mathrm{O}$ humor da cena fica por conta dos itens comestíveis que ela menciona para Stanley: uma lata vazia de pó saborizado Quick contendo prendedores para sacos de lixo, gomas de mascar, Hostess Twinkies (uma espécie de bolo recheado Ana Maria), peanut brittles (algo próximo ao pé de moleque brasileiro), barras de chocolate Hershey, tirinhas de alcaçuz e um pote de cookies Aunt Jemina. Os doces são populares e as marcas mencionadas são bastante tradicionais nos Estados Unidos, produzindo um efeito - muito bem engendrado por Durang - de afirmação da "americanidade" de Stanley, nacionalidade que ele faz questão de reforçar no início da peça ao dizer "Eu não sou polaco! Sou americano!", ${ }^{24}$ ao mesmo tempo reforçando sua imaturidade quase infantil, pela forma como responde às falas de Blanche e à situação da peça em geral.

Blanche pergunta se ninguém tentará demovê-la da ideia do suicídio, recebendo uma reação mecânica de apoio por parte de Cora e a sugestão de usar a passagem de ônibus que Stanley comprou para ela. Na peça-fonte, a compra da passagem por Stanley é dada a Blanche no dia de seu aniversário, como um "presente cruel” para que ela vá embora. Em Desire, desire, desire, Blanche recusa-se a usar a passagem com destino a Glengarry Glen Ross, local que parodia o título da peça homônima de David Mamet, em que corretores devem vender terrenos indesejáveis em meio a um ambiente altamente competitivo. A própria descrição de Stanley revela quão inóspito o lugar pode ser. Mesmo quando a ataca para

22 "broken dreams and extra filters for the vacuum cleaner." (DURANG. Naomi in the living room and other plays, p. 198, tradução nossa).

23 "scattered pieces of my heart." (DURANG. Naomi in the living room and other plays, p. 198, tradução nossa).

24 "I am not a Polack! I am an American!" (DURANG. Naomi in the living room and other plays, p. 193, tradução nossa). 
que seja realista, ela devolve, na paródia, a mesma frase da Blanche da peça-fonte: "Eu não quero a realidade. Eu quero a magia." ${ }^{25}$ É a magia, ou melhor, a ilusão de que o mundo pode ser recriado à sua medida, que a leva à derrocada no texto de Williams.

O Jovem fica um tempo sem falar e depois diz que vai se tornar vice-presidente da Home Box Office (canal HBO), descreve filmes comerciais (por exemplo, dramas sobre deficientes físicos que correm as Olimpíadas com perna de pau) e, perguntado por Blanche se ele não se interessaria em produzir a história de "[u]ma mulher com ilusões destruídas, vivendo em um lugar onde a morte está tão perto quanto você está, e onde o contrário de morte é desejo. Desejo, desejo, desejo." ${ }^{26}$ Ele responde que a história dela não é suficientemente comercial. A fala de Blanche na peça-fonte, enquanto uma mulher mexicana vende flores, é dada numa cena com atmosfera quase fantasmagórica, com a personagem lembrando das dificuldades que teve ao acompanhar os familiares morrendo e depois contando ao seu pretendente como se envolveu com os jovens soldados do acampamento. A resposta do Jovem lembra um tema recorrente nas peças paródicas de Durang, qual seja, a representação da mulher na arte. Na introdução deste artigo, exemplificamos como isso acontece na Medea do autor.

Com nova interrupção na entrevista do Jovem, chegam Paizão e Maggie 2, seguida de Maggie, novamente para confundir Stanley com Brick e inquirir porque ele (Brick) não tem um filho com Maggie. Maggie 2 explicitamente convida Brick para se deitarem, pois ela está no período fértil. Maggie 2 e Maggie afirmam querer ter o filho de Brick, e Maggie 2 levanta a hipótese de que ele não vai para a cama com ela por causa de Skipper, seu suposto amante. Enquanto Paizão vai e volta para a cozinha dizendo "mendacidade" (hipocrisia, falsidade, deslealdade), palavra que expressa o tema de Cat on a hot tin roof, Blanche mostra-se estressada por não ser o centro da atenção e Stanley, para surpresa de todos, em vez de gritar o nome da esposa, como vinha fazendo desde o início da peça, chama em alto e bom som por Skipper. É neste momento

\footnotetext{
25 "I don't want realism. I want magic." (DURANG. Naomi in the living room and other plays, p. 199, tradução nossa).

26 “A woman with illusions shattered, livin' in a place where death is as close as you are, and where the opposite of death is desire. Desire, desire, desire." (DURANG. Naomi in the living room and other plays, p. 199, tradução nossa).
} 
que Durang vai desconstruir na peça a noção de heteronormatividade, tão cara ao Stanley de $A$ streetcar named desire e que já se encontrava posta em discussão em Cat on a hot tin roof, pois o sofrimento de Brick advém do suicídio do amigo (suspeito amante) Skipper: ele abraça o Jovem e faz um breve discurso sobre como Maggie vê indecência em tudo, como ele e Skipper são amigos que fazem coisas comuns acompanhados, como dar as mãos, tomar banho juntos, beijar na boca vestidos de lenhador, sem que isso represente nenhuma sujeira. A fusão do discurso de Brick em Cat on a hot tin roof, em que ele se defende da esposa dizendo que sua amizade com Skipper é terna, com o de Stanley/Brick em Desire, desire, desire, aponta para representação de um novo desenho social em que a sexualidade não pode mais ser vista como algo estanque e imutável. Stanley propõe, naquele momento, experimentar uma orientação sexual até então nova para ele.

Lembrando que a peça é de 1995 e pouco mais de dez anos antes havia explodido a epidemia da Aids, chamada injusta e preconceituosamente de gay plague (peste gay), compreende-se o desafio de tocar no assunto da homossexualidade tendo como referência Stanley Kowalski, um dos personagens mais másculos e viris da história do teatro e do cinema estadunidense. Retornando brevemente a Hutcheon, ${ }^{27}$ a autora afirma que "Mesmo ao escarnecer, a paródia reforça; em termos formais, inscreve as convenções escarnecidas em si mesma, garantindo, consequentemente, a sua existência continuada". Durang provoca a plateia através de um ícone de masculinidade, e a paródia, por seu caráter de ironia, tem o poder tanto de suscitar quanto de aliviar tensões, sem que com isso a figura do Stanley da peça original e dos filmes seja arranhada.

Não entendendo bem o que está se passando, o Jovem sai com Stanley/Brick, seguido das duas Maggie e de Paizão, deixando Blanche completamente sozinha na casa. Durang, astuciosamente, insere a paródia da cena de Blanche ao telefone pedindo auxílio de um operador para enviar um telegrama urgente pedindo socorro a um amigo de longa data chamado Shep Huntleigh. Na paródia, o operador menciona o nome de Samuel Beckett, que Blanche diz não conhecer. A introdução do nome de um dos maiores ícones do teatro do absurdo, autor de clássicos como Esperando Godot e Fim de partida, marca o alto refinamento da paródia, pois através de uma fala metalinguística Blanche afirma não conhecer

${ }^{27}$ HUTCHEON. Uma teoria da paródia, p. 97. 
um "criador de situações" parecidas com aquela na qual ela está imersa no momento, reconhecendo que nada pode fazer, exceto esperar pelo retorno de sua irmã, o que acontece exatamente em seguida.

A Stella de $A$ streetcar named desire é apaixonada por Stanley e, apesar de suas agressões a ela e à irmã, acaba ficando com ele na expectativa de um futuro feliz a dois. Durang reverte a situação, pois Stella retorna à casa apenas brevemente. Ao saber por Blanche que Stanley foi para um motel com o Jovem/Skipper, ela simplesmente diz: "Ah, Stanley, ele é tão brincalhão." 28 e sai para buscar o refrigerante correto para Blanche, prometendo retornar em breve. Blanche, sozinha novamente, reconhece que a irmã vai demorar mais seis anos para retornar e faz uma série de citações a nomes de peças, incluindo uma do próprio Durang, For whom the southern belle tolls (Por quem as belas sulistas dobram), peça que parodia o título do romance For whom the bell tolls (Por quem os sinos dobram), de Ernest Hemingway, e a peça The glass menagerie ( $\grave{A}$ margem da vida/O zoológico de vidro), de Tennessee Williams. Blanche, assim como a Amanda Wingfield de The glass menagerie, é uma "bela sulista", nome geralmente atribuído a mulheres que pertenciam (ou intencionavam pertencer) a uma classe social superior, cultivavam a beleza e procuravam manter uma aparência de comportamento casto.

O final da peça se aproxima e um homem aparece à porta, em traje de coelho, dizendo "Flores. Flores para os mortos", ${ }^{29}$ fala da mulher mexicana em $A$ streetcar named desire. Blanche lhe pergunta se ele é o Harvey da peça de Mary Chase, ao que ele nega. Ela, então, afirmando que não importa quem seja, repete a frase mais famosa da peça-fonte: "Eu sempre dependi da bondade de estranhos." 30 Como duas realidades que se entrecruzam, a Blanche da paródia agora depende da bondade de um estranho, assim como a personagem da peça de Williams dependeu do médico que a trata com gentileza (outra tradução possível para kindness) antes de levá-la para a instituição onde receberá tratamento após o colapso causado pelo ataque de Stanley.

28 "Oh, Stanley, he is such a card." (DURANG. Naomi in the living room and other plays, p. 202, tradução nossa).

29 "Flores. Flores para los muertos." (DURANG. Naomi in the living room and other plays, p. 203, grifo do autor, tradução nossa).

30 "I have always depended on the kindness of strangers." (DURANG. Naomi in the living room and other plays, p. 203, tradução nossa). 
A Blanche da peça curta tem mais sorte e o homem travestido de coelho revela-se Stanley. Ele admite que o ocorrido com Skipper/Jovem era apenas uma "fase". O traje, segundo ele, é para usar quando Stella tiver o bebê, mas quando é inquirido por Blanche sobre a gravidez dela, admite que não a vê há seis anos. Blanche conta que Stella retornou por alguns instantes e já foi embora. A peça se encerra com Stanley repetindo a frase da peça longa em que diz a Blanche que eles tinham um encontro marcado desde o início (leia-se, um encontro sexual) e ela lhe agradece por dizer algo tão doce, o que evidentemente não acontece na peça longa. Ele torna a chamar por Stella e ela encerra sua fala com as palavras do título - desejo, desejo, desejo -, enquanto veste a cabeça de coelho e senta-se com ar triste e trágico. É certo que Stanley não enlouquece, como Blanche no texto de Williams, mas sua postura de homem seguro e capaz de enfrentar qualquer obstáculo é desfeita por Durang ao final da peça, pois ele retorna ao mesmo ciclo de lamentação do início, chamando por Stella, e Blanche permanece ao seu lado. $\mathrm{O}$ ato de vestir a cabeça do coelho, como bem observado por Khalil, dialoga com o "[...] final de Harvey quando Veta [irmã de Elwood], num gesto de aceitação, impede o médico de dar a ele uma injeção que iria torná-lo um ser humano normal." ${ }^{\prime 1}$

\section{Considerações finais}

Esta peça de Durang exige do leitor/espectador uma mobilização de conhecimentos provenientes da cultura teatral estadunidense, preservados nos textos originais e propagados nas adaptações cinematográficas e televisivas, nas inúmeras referências constantes em outras peças, nos seriados de televisão, isto é, já estão incorporados na cultura.

O autor estabelece um diálogo entre a época "dourada" do teatro e cinema dos anos pós-guerra, em que ainda fazia sentido um discurso uniformizador, e o fim de século, no qual tudo estava sendo revisto e reanalisado, com novas concepções se instaurando no tecido social. Durang propõe uma releitura paródica desses clássicos, sem a intenção

31 “[...] Harvey's ending when Veta stopped the doctor before giving Harvey an injection that was going to turn him into a normal human being as a sign of acceptance." (KHALIL. Revisiting the Theatre of the Absurd in Christopher Durang's For whom the Southern belle tolls (1993) and Desire, desire, desire (1995), p. 149, tradução nossa). 
de desconstruí-los ou destruí-los, porque eles fazem parte da história literária, teatral e cultural de seu país, sendo portadores de conhecimento sobre aquela sociedade. Sua proposta é mais modesta e, por isso mesmo, mais viável, lógica e produtiva para seus apreciadores.

Os lugares sociais, tão delimitados e defendidos em $A$ streetcar named desire e Cat on a hot tin roof, são agora relativizados e modificados na releitura paródica. Blanche não termina a vida numa instituição para tratamento mental. Seu egoísmo e desejo de remodelar o mundo à sua imagem não têm mais lugar na sociedade atual, o que fica representado por seu discurso ao qual ninguém presta atenção. Também não consegue uma relação estável com Stanley, que ainda está obcecado com a (ex-) esposa Stella, mas permanece a seu lado. Não há mais lugar para a ideia de morte, como havia em $A$ streetcar named desire, talvez por isso Durang não tenha parodiado o conhecido trecho ao final da peça em que ela fala sobre morrer e ser sepultada no mar. Stanley, aparentemente de uma virilidade heterossexual imutável, experimenta uma ampliação temporária de objeto de interesse, ao não aguardar por Stella e se envolver com o Jovem/Skipper. Stella, por sua vez, não se importa com as ações do marido e nem precisa estar inserida em uma família. Ela não se choca ao saber do breve caso dele com outro homem e deixa a casa para voltar apenas quando bem entender.

Nas peças do absurdo há uma suspensão da lógica tradicional, isto é, enredo com começo, meio e fim em que as ações se encadeiam em torno de um objetivo central pelo qual protagonista e antagonista competem, porém, essas peças não deixam de propor uma ou mais ideias, afinal o sentido maior do teatro (e da arte em geral) é provocar a reflexão. Christopher Durang, com muito humor e repleto de referências, convida o público a repensar a sociedade atual - tanto à época da escrita/encenação da peça quanto o presente - a partir da fusão de várias narrativas e personagens numa peça na qual nada ou muito pouco é lógico, mas tudo tem um sentido passível de compreensão aos que tiverem o desejo de aprender com a paródia e seus efeitos. 
Aletria, Belo Horizonte, v. 29, n. 1, p. 91-109, 2019

\section{Referências}

ALFARO, Maria Jesús Martínez. Intertextuality: origins and development of the concept. Atlantis, Madrid, v. 18, n. 1-2, p. 268-285, jun.-dic. 1996. Disponível em: $<$ http://faculty.weber.edu/cbergeson/quixote/martinez. pdf $>$. Acesso em: 20 ago. 2018.

ARISTÓTELES. Poética. Tradução, textos adicionais e notas de Edson Bini. São Paulo: Edipro, 2011.

CHRISTOPHER Durang. Disponível em: $<\mathrm{http}$ ://www.christopherdurang. com/>. Acesso em: 5 set. 2018.

DURANG, Christopher. Naomi in the living room and other plays: a collection of one-acts by Christopher Durang. New York: Dramatists Play Service, 1998.

HUTCHEON, Linda. Uma teoria da paródia. Lisboa, Rio de Janeiro: Edições 70, 1985.

INTERTEXTUALIDADE. In. GRANDE Dicionário Houaiss. [s.n.t]. On-line. Disponível em: <https://houaiss.uol.com.br/pub/apps/www/ v3-3/html/index.php\#3>. Acesso em: 16 set. 2018.

KHALIL, Hend Mohamed Samir Mahmoud. Revisiting the Theatre of the Absurd in Christopher Durang's For whom the Southern belle tolls (1993) and Desire, desire, desire (1995). Arab World English Journal, Richmond, TX, n. 3, p. 138-152, Oct. 2015. Disponível em: <https:// papers.ssrn.com/sol3/papers.cfm?abstract_id $=2843965>$. Acesso em: 30 ago. 2018.

SZONDI, Peter. Teoria do drama moderno [1880-1950]. Tradução de Luiz Sérgio Repa. São Paulo: Cosac Naify, 2001.

TELES, Gilberto Mendonça. A retórica do silêncio: teoria e prática do texto literário. São Paulo: Cultrix, 1979.

WILLIAMS, Tennessee. Cat on a hot tin roof. In: . The theatre of Tennessee Williams. New York: New Directions, 1990. v. 3: p. 01-215.

WILLIAMS, Tennessee. Um bonde chamado desejo. Tradução de Vadim Nikitin. São Paulo: Peixoto Neto, 2004.

Recebido em: 29 de setembro de 2018. Aprovado em: 16 de janeiro de 2019. 